\title{
Publication pressure threatens the integrity of palaeontological research
}

Nussaïbah B. Raja (nussaibah.raja.schoob@fau.de, @mauritiantales) \& Emma M. Dunne (dunne.emma.m@gmail.com, @emmadnn)

This manuscript has been submitted for publication in The Geological Curator and is undergoing peer-review. Please note that the manuscript has not been formally accepted for publication and is as such a non-peer reviewed preprint. Subsequent versions of this manuscript may have slightly different content. If accepted, the final version of this manuscript will be available via the Peer-review Publication link on this web-page. Feel free to contact us if you have any queries or comments; we welcome any feedback that you may have. 


\title{
Publication pressure threatens the integrity of palaeontological research
}

\author{
Nussaïbah B. Raja ${ }^{1, \bowtie}$ and Emma M. Dunne ${ }^{2}$ \\ ${ }^{1}$ GeoZentrum Nordbayern, Department of Geography and Geosciences, Friedrich-Alexander University Erlangen-Nürnberg, Erlangen, Germany \\ ${ }^{2}$ School of Geography, Earth and Environmental Sciences, University of Birmingham, Edgbaston, Birmingham, B15 2TT, UK
}

Publications are the de facto currency of academia. Academics, palaeontologists included, are often judged by publication metrics, which usually include the impact factor of the journal in which they publish, the number of publications and the number of citations. However, in the race to publish in high-impact journals and the pressure to increase research productivity, sometimes corners are cut, leading to an increase in scientific and other types of misconduct. In this paper, we demonstrate how ethical, and even legal, transgressions within palaeontology, particularly regarding the provenance of fossil specimens, are inherently related to the pressure faced by academic researchers to publish "novel" studies in high-impact journals. We note how papers in high-impact journals follow a consistent theme of either showcasing novel evidence or methods, or describing charismatic or unusual specimens, often dinosaur-related. We examine notable recent examples of these papers that have been linked to ethical and legal problems, which have ironically been brought to light by virtue of the paper being widely publicised as highly "impactful". Finally, we discuss the importance of developing an ethical framework for scientific publishing, which currently does not exist; only a handful of professional palaeontological bodies, including societies and journals, have independently developed policies to combat these issues. While the culture of "publish or perish" lingers in palaeontology, there will be no incentive for more ethical research that better serves both science and society to prevail.

publication pressure | research ethics | paleontology | academia | scientometrics

Correspondence: nussaibah.raja.schoob@fau.de

\section{Publication pressure in academic circles}

"Publish or perish" has become the expression that describes modern academic culture where academics, palaeontologists included, face increased pressure to boost their research output in the form of publications (1-4). Publications have become the de facto currency of academia, however, not all publications are made equal: there are several factors that come into play when deciding what gets to be published and where.

The journal impact factor (JIF; the yearly mean number of citations received by publications published in a given journal over the two previous years) has been the staple of the academic publishing industry since 1975 (5). JIF is one of the metrics used to rank academic journals, with journals such as Nature and Science appearing at the top, and by extension, often being used as a measure of scientific merit or quality $(6,7)$. JIF is not only used to decide where to submit research publications but also by funding or institutional committees, together with the h-index (a similar metric that measures both the productivity and citation impact of a scientist's publications), to make decisions on jobs, promotions or grants (8-11). Applicants with publications in high-impact journals tend to receive better scores than those with publications in middle or low-impact journals, despite the fact that the delineation between high, middle and low tiers is arbitrary (11). As a result, early-career researchers are advised not to focus their attention on low-impact publications as this may affect their future job prospects where high-impact publications are typically one of the criteria used to judge applicants $(8,12,13)$. In many European and North American institutions, a list of journals and their JIFs is usually provided to hiring committees to evaluate candidates (14). Metrics such as the JIF offer a convenient way to judge applicants, but are inherently flawed with respect to quality and influence (12). To start with, JIF was never originally intended to be used to judge individual researchers, but rather to understand the impact of a journal as a whole over a certain period (9). Generally, the number of citations of publications in a given journal follows a highly skewed distribution, with the number of citations of a specific publication being generally lower than the journal's impact factor. As such the JIF does not fully portray the number of citations a particular publication may receive (15). While JIF-free assessments exist, these have yet to be established in the wider academic community (16).

Worryingly, this pressure to publish high-impact papers can result in the publication's projected "impact" trumping other important considerations. Until recently, Chinese universities awarded bonuses to researchers publishing in highimpact journals - a policy that is said to have incencitised researchers to focus on quantity over quality, and to commit malpractices such as plagiarism or citation inflation (17). In fact, there is a positive correlation between the journal impact factor and the number of retractions for any given time period, i.e. journals with higher impact factors generally face more retractions $(18,19)$. The primary reason for retractions in scientific disciplines over the last two decades have been scientific fraud (fabrication, falsification, plagiarism) or other kinds of misconducts (e.g. fake peer review) (20). Pressure to publish "novel" results in high-impact journals has previously been linked to decreased ethical standards $(21,22)$, and may explain how some authors place "publication prestige" above other aspects of their work, such as research ethics and legality.

The discipline of palaeontology is not exempt from such malpractices, although retractions are rare-only five out 


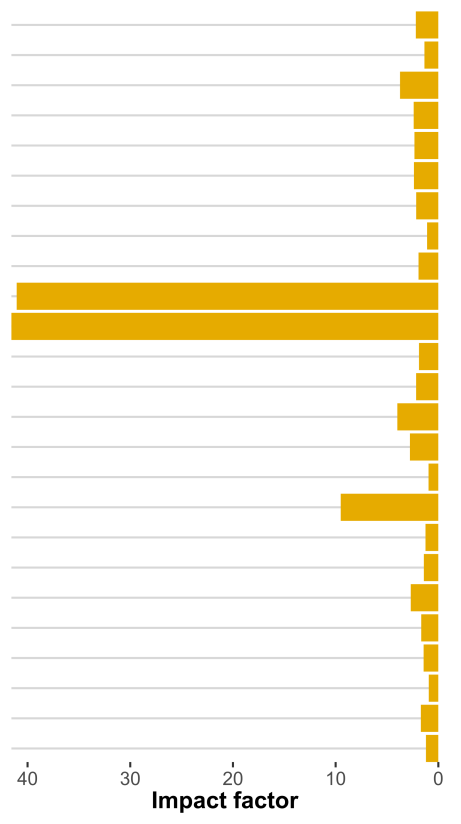

$$
\begin{gathered}
\text { J. Vertebr. Paleontol } \\
\text { J. Paleontol. } \\
\text { Paleontology } \\
\text { Paleobiology } \\
\text { J. Syst. Palaeontol. } \\
\text { P3 } \\
\text { Pap. Palaeontol. } \\
\text { Palaeoworld } \\
\text { Cretac. Res } \\
\text { Science } \\
\text { Nature } \\
\text { Acta Palaeontol. Pol. } \\
\text { Quat. Int } \\
\text { J. Hum. Evol } \\
\text { PLoS One } \\
\text { Swiss J. Palaeontol. } \\
\text { PNAS } \\
\text { Hist. Biol. } \\
\text { Palaeontol. Electron. } \\
\text { Zool J Linnean Soc } \\
\text { Rev. Palaeobot. Palyno } \\
\text { C R Palevol } \\
\text { Zootaxa } \\
\text { Palaios } \\
\text { Geobios }
\end{gathered}
$$

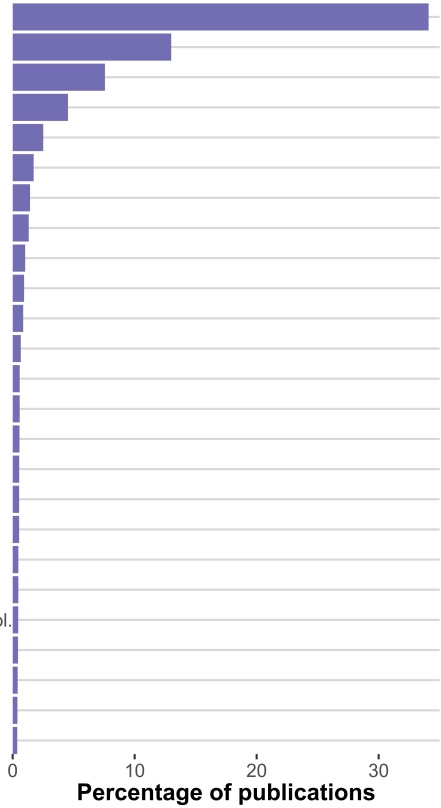

Fig. 1. The top 25 journals in palaeontology with their impact factors and the percentage of indexed palaeontological publications published within them. Based on data from the Web of Science (using the following keywords in the search: "paleontology OR palaeontology OR paleobiology OR palaeobiology"). Abbreviations of journal names: J. Vertebr. Paleontol., Journal of Vertebrate Paleontology; J. Paleontol, Journal of Paleontology; J. Syst. Paleontol., Journal of Systematic Palaeontology; P3, Palaeogeography, Palaeoclimatology, Palaeoecology; Pap. Palaeontol., Papers in Palaeontology; Cretac. Res, Cretaceous Research; Acta Palaeontol. Pol., Acta Palaeontologica Polonica; Quat. Int., Quaternary International; J. Hum. Evol., Journal of Human Evolution; Swiss J. Palaeontol., Swiss Journal of Palaeontology; Hist. Biol., Historical Biology; Palaeontol. Electron., Palaeontologia Electronica; Zool J Linnean Soc, Zoological Journal of the Linnean Society; Rev. Palaeobot. Palynol., Review of Palaeobotany and Palynology; C R Palevol, Comptes Rendus Palevol. of 23,000 publications were retracted during the period 1990-2021, three of which were published in Nature and one in $P N A S$, according to PubMed.gov. Despite the rarity of retractions in palaeontology, several publications in highimpact journals have actually increased the visibility of certain malpractices that occur within the discipline of palaeontology (23). In this paper, we demonstrate how ethical, and even legal, transgressions within palaeontology are inherently related to the pressure faced by academic researchers to publish "novel" studies in high-impact journals.

\section{Publication trends in palaeontology}

Traditionally, palaeontological research has focused on the discovery, description, and form and function of fossil organisms. In more recent decades, palaeontological research has shifted to also encompass broader scale macroevolutionary and palaeobiological analyses of diversity, evolution and extinction through deep-time, particularly following the computational work of David Raup and Jack Sepkoski $(24,25)$. Palaeontological research is most often published in palaeontology-specific journals, for example Journal of Vertebrate Paleontology and Palaeontology (Fig. 1). These journals, while they publish a wide range of palaeontological research from species-specific taxonomic descriptions to broadscale macroevolutionary studies, typically have a JIF of less than 5 and may be considered "low-impact" journals (Fig. 1). On the other hand, palaeontological studies published in journals with the highest JIFs, i.e. Nature and Science, are most likely to document a newly-acquired fossil specimen or uncover "new evidence" of some aspects of a group's evolutionary history, as illustrated by the titles of these publications (Fig. 2), which reflect their editorial criteria to publish on "outstanding" or "influential" scientific topics $(26,27)$. Unsurprisingly, the most "popular" papers in these high-impact journals are on dinosaur specimens, as re- flected in the number of social media posts and media reports based on these publications (Fig. 3). This is unsurprising given that they are one of the most famous groups of ancient animals among scientific and non-scientific audiences alike (28). However, the winning combination in terms of popularity comes in the form of dinosaur related specimens preserved in amber (Fig. 3), particularly amber from Kachin State, in the northern region of Myanmar. One particular publication in Nature Communications that described the feeding behaviour of insects on dinosaur feathers (29) was picked up by 68 media outlets in multiple countries, and was shared by more than 500 users on Twitter as of May 2021. However, as discussed further in the next section, not all press is good press. The popularity of some high-impact publications in the media has led to the exposure of certain ethical and legal transgressions (30).

As the prestige of an academic journal depends, at least partly, on how often the research articles it publishes are cited, "novel" or surprising scientific findings are viewed as more desirable by journals (7). This publication bias is pervasive across all scientific disciplines $(7,31)$, but is especially prevalent in highly competitive fields (32). In palaeontology, there is a pressure to publish in high-impact journals such as Science, Nature, and PNAS, but only a small proportion of palaeontological studies appear in these journals (Fig. 1). The quest for novelty in scientific studies can not only encourage authors to commit various transgressions, but is also a major obstacle to addressing gaps in the literature. In palaeontology, this translates to the increasing rarity of classic taxonomic and systematic work i.e. the description and classification of species, especially of less "charismatic" organisms. This work is essential for nearly all studies in palaeontology, as well as natural sciences more broadly, since species are fundamental units in analyses of evolution, diversity, and extinction $(33,34)$. Taxonomy and systematics pa- 


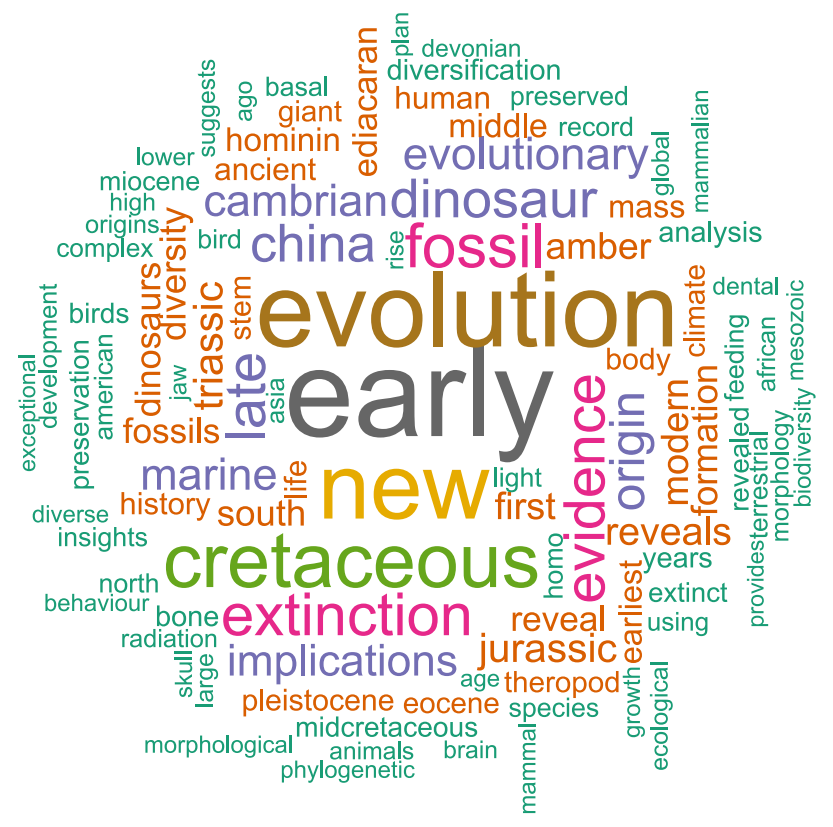

Fig. 2. Word cloud of the top words used in the title of palaeontological publications in the Springer Nature group and Science journals published during the period December 2015 to November 2020. The size of the word represents its frequency, i.e. the bigger the word, the more often it is used in article titles. Common determiners, conjunctions and prepositions (e.g. "the", "a" or "in") were excluded.

pers are increasingly treated as obscure specialised publications, lacking the perceived prestige required for publication in high-impact journals (35). In fact, JIF has been shown to be inadequate for assessing taxonomic publications. In 2019, the mega-journal Zootaxa, which caters for publications on zoological taxonomy, was suppressed (later reversed after the scientific community protested) due to the high proportion of self-citations from the Journal Citation Report that publishes statistics about journals including the JIF (36). Self-citations can usually be a sign of artificial inflation of JIF. However, given the nature of the field of taxonomy (i.e. the high number of specialists, and the fact that not many journals actually cater for taxonomic studies), self-citations are not surprising and sometimes cannot be avoided especially when references to previous taxonomic work, often carried out by the same people for a specific taxonomic group, are needed. As such, JIF is not meaningful when it comes to determining the quality of these publications and instead may bring more harm to taxonomic endeavours by sending the message that this expertise is not valued in science.

\section{Ethical and legal transgressions in palaeon- tology}

Recent palaeontological studies describing new fossil species in high-impact journals have highlighted a number of issues involving ethics, legality, and reproducibility within the field of palaeontology $(23,30)$. In several cases, these publications involve violations of national fossil laws and the use of fossil repositories that are not widely accessible to other researchers. In the most extreme cases, these fossil specimens have even been linked to human rights violations.

On 11 March 2020, a paper describing a specimen preserved in amber from Myanmar, thought to be a bird-like dinosaur, was published in Nature (37). The paper was retracted three months later, on 22 June 2020 after Nature launched an investigation following the publication of a preprint (now published in Vertebrata PalAsiatica) on the bioRxiv server by another group of palaeontologists who reanalysed the original computer tomography data and demonstrated that the specimen in fact showed lizard-like features (38). While the retraction itself was not the result of any apparent fraud (39), the publication of this study brought an important issue further into the spotlight: the controversies around Myanmar amber (also referred to as Burmese or Kachin amber), particularly its links to human rights abuses by the Myanmar military on ethnic minorities in the northern state of Kachin, where most amber from Myanmar is mined (40).

The issues around Myanmar amber had been widely known before this 2020 paper was published $(41,42)$. However, as a result of this publication appearing in a high-impact journal as well as on the cover of that issue (43), discussions around these controversies were rekindled across the palaeontological community. On the same day as the Nature paper was published, an article covering the ethical issues with Myanmar amber was also published in the New York Times, featuring one of the authors of the publication making a case for research on Myanmar amber despite any ethical concerns due to the scientific importance of this material (40). This has led to more heightened debates about how such ethical, societal and human rights issues should be handled with regards to palaeontological research. In April 2020, the Society of Vertebrate Paleontology released a letter addressed specifically to journal editors calling for them to declare a moratorium on all amber specimens acquired from Myanmar after June 2017, which coincides with the time that the military forces 
Includes "dinosaur" in title

Does not include "dinosaur" in title

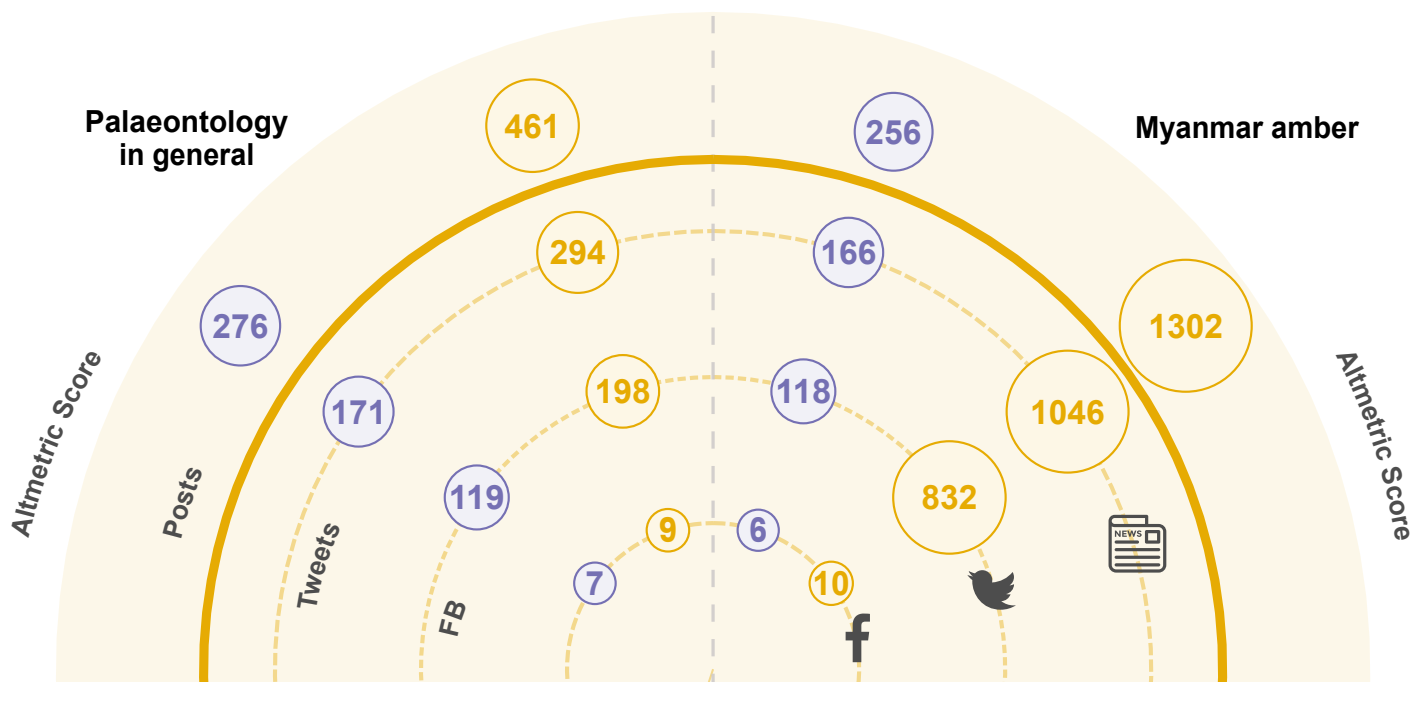

Fig. 3. Altmetric scores and the number of blog posts, tweets, and facebook (FB) posts (as of December 2020) belonging to all palaeontological publications (left) and those on Myanmar amber only (right), published in the Nature group and Science journals during the period December 2015 - November 2020 . The altmetric score is a weighted score of the attention a publication has received in the news and on social media.

in Myanmar started their campaign to take over the amber mines in the Kachin State (44). This letter was criticised by several members of the palaeontological community (45-47), but was also received positively by some journals such as the Journal of Systematic Paleontology (48) and Acta Palaeontologica Polonica (49), which are both popular palaeontology journals (Fig. 1).

As the palaeontological community continues to debate whether (and how) ethical issues such as human rights abuses should be considered within the scope of research ethics, issues of legality around fossils have been extensively documented e.g. Liston \& You (50) and Meijer (51). Over the last two decades, several countries, such as Brazil, China and Mongolia have been cracking down on violations of their existing fossil laws that restrict or outright ban exports of fossil specimens (30). Brazil has banned the export of fossils uncovered on Brazilian soil for over half a century since 1942, and since 1990 requires foreign researchers to work in collaboration with a local scientific institution. As such, when the description of a new Brazilian fossil, Tetrapodophis amplectus, was published in Science (52), questions were raised regarding its provenance, as the specimen was reportedly reposited in a private collection in Germany. The study had also not involved any Brazilian researchers or institutions, and a legal investigation was launched (51-53). More recently, a Brazilian dinosaur specimen named "Ubirajara jubatus", which was described in a publication in Cretaceous Research on 13 December 2020 came under scrutiny for similar reasons, and was temporarily retracted (and remains retracted at the time of writing) while an investigation is underway (54). Another controversial specimen, this time a ray- like shark specimen from Mexico named Aquilolamna milarcae, was published in Science in March 2021 (55). This fossil sparked controversies because it had been purchased and, at the time of its publication, was being housed in a private collection (until a new museum is built). Both the purchase of fossil material and housing fossils in private collections are prohibited under Mexican fossil laws $(30,56)$. After the initial publication, the authors resolved both issues, firstly by moving the specimen to a museum where it will apparently be accessible to other researchers (again, until the new museum is ready) (57) and secondly, by removing information about the specimen having been purchased to the supplementary materials (58), likely in an attempt to disguise this violation (30).

Myanmar amber is also controlled by the national legislature, but loopholes in the law can and do allow for rampant exploitation. Any fossil specimen leaving Myanmar (e.g. for study or temporary display) requires permission from the necessary authorities and cannot be marketed according to the 1957 Antiquities Act, revised as the The Protection and Preservation of Antique Objects Law in 2015 (23). Amber is classified as a gemstone under the Myanmar Gemstone Law and thus can be sold and exported with the appropriate permits. However, neither the Antique Objects Law nor the Gemstone Law addresses the presence of fossils in amber, leaving the acquisition of amber specimens with fossil inclusions within a so far unaddressed complex legal greyzone (23). In many circumstances, this legal loophole is used by researchers to affirm that their amber specimens were legally acquired and that no legal issues exist with regards to Myanmar amber specimens $(23,40,42)$. However, until this is 
addressed specifically by the Myanmar government - a very difficult feat given the military coup in the country in February 2021 - researchers remain liable for not abiding to national fossil laws in Myanmar whose penalties include fines and even imprisonment. Until a legal precedent is set, researchers should thus abide by national laws regarding fossils, which state that specimens must be reported to the authorities and reposited in a national repository, or if being exported for study or display, a permit should be acquired.

\section{Towards building an ethical framework}

Research ethics are not new to palaeontology. Palaeontologists, like other scientific researchers, have a responsibility to uphold certain ethical requirements during their research to avoid scientific misconduct. However, what is unclear is what falls under the term "scientific misconduct" within palaeontology. While falsified research or plagiarism unanimously would come under this umbrella, other considerations such as socioeconomic and political issues are less definitive. Many professional societies, such as the Paleontological Society and the Society for Vertebrate Paleontology now have codes of conduct that their members must abide by, covering professional and personal conduct as well as the provenance of fossil material, among other considerations $(59,60)$. However, these societies seem to be among the very few that have such policies for their members. It must also be noted that these professional societies operate on an honour system and cannot legally enforce these policies.

Similarly, many journals have ethical considerations for their authors, usually informed by, but not restricted to, the Committee of Publication Ethics (COPE), whose aim is to educate and support publishers and editors on publication ethics (61). As of 16 May 2021, only a handful of palaeontological journals, including Cretaceous Research, Palaeontology and the Swiss Journal of Palaeontology and broader (and highimpact) journals including Nature and Science are members of COPE. However, the COPE's core practices only cover ethical issues when the subject of research requires ethical considerations, such as research on animal or human subjects, but not when research is linked to human rights abuses (unrelated to the subject of research) or for matters of legality. Many palaeontological journals however have their own editorial policies, at least regarding the latter. For example Palaeontology and Papers in Palaeontology require "clear provenance information to ensure full transparency of the research methods" and that specimens collected "from protected sites should include information regarding the requisite permission obtained" (62). The journals Journal of Vertebrate Paleontology and Journal of Systematic Palaeontology explicitly state that they do not accept manuscripts based on specimens in amber from Myanmar $(44,48)$. Editorial policies at Cretaceous Research state that "fossil material of uncertain or dubious provenance will not be accepted for publication" (63). This points to the fact that these policies are being individually developed without any central ethical framework across the discipline. In the case of Creta- ceous Research, these policies are not being upheld, judging by the number of publications on Myanmar amber that have appeared in this journal (54 in 2021 as of 16 May 2021, based on a search using the keywords "Myanmar amber OR burmese amber OR kachin amber"), even after the controversies around the material was openly known. Until all journals catering for palaeontological research enforce similar policies with regards to ethics and legality, there will always be an avenue for work involving unethical or illegal research practices.

Similarly, research institutions and funding organisations, just like professional societies and journals, should also be committed to high standards of ethics. Palaeontological departments and institutions should provide training to their staff and students regarding ethical issues within the discipline, especially as these become more well-known and acknowledged. Palaeontology has long operated outside the ethical lens, mainly due the nature of the discipline itself which focuses on ancient life since the time before humans existed. However, this does not mean that palaeontology is in any way exempt from ethical considerations. The examples we provide here do not represent the full extent of ethical issues within the field of palaeontology and geosciences. Parachute science, lack of diversity, sexual harassment, racism, ableism, and bullying are just some of the other issues that need to be addressed by the discipline (64-70). Often, the reaction of academic institutions to misconducts committed by members of their staff is inadequate, especially when these people tend to be in powerful and influential positions $(71,72)$. Due to their competence in publishing in high-impact journals and winning large grants, thus providing more visibility and resources for the institution, there is considerable institutional support shown to these individuals. Similarly, funders should be more critical of ethical and legal problems persisting in palaeontology. Funding frequently comes from national agencies through taxes. As such, increased transparency from individuals, groups or institutions receiving public funding should be a fundamental requirement. In the case of Myanmar amber, for example, public funding may be contributing to armed conflicts and human rights abuses in the Kachin State through the commercialisation of amber, which is a known source of revenue for the armed military forces inflicting these injustices on the ethnic minorities in the country (73).

\section{Eliminating the "publish or perish" culture}

As long as the culture of "publish or perish" remains ubiquitous in palaeontology, researchers will continue to place publication prestige ahead of ethics and other concerns. Publication metrics should not be the primary criteria by which scientists are judged for career progression, awards, and research grants. An increasing number of publications include spin or "science hype" in their titles, such as the overuse of the words "new" or "novel", to make them more attractive to high-impact journals (Fig 2) $(74,75)$. The pressure to publish "novel" or surprising results in high-impact journals is also 
likely to be exacerbated by the precariousness of scientific careers (76), which is particularly pertinent in the wake of the COVID-19 pandemic. Academic metrics also discriminate against marginalised groups that, on average, have fewer publications due to systemic biases and other duties, such as higher teaching load, higher mentorship load, and caring responsibilities (77-80). These factors are rarely taken into consideration during assessments for jobs, awards, and grants. The culture of continuously seeking high-impact publications can also lead early career researchers to narrowly focus their work on output that is most suited for these publications. Creativity in research, which can lead to innovative methods and discourses, does not always have a place in modern scientific environments (81). The academic job market has become rigid and narrow, prescribed by the same requirements made by different departments and overly focused on publications and grants, that academics have no choice but to conform to these standards in order to secure a tenured academic position, which is already limited in terms of number of available permanent positions (82). Funders also frequently have certain restrictions on grants provided, such as the number of years after $\mathrm{PhD}$ for starting grants e.g. the European Research Council (83). This system puts those who might have taken a academic break for personal or professional reasons at a disadvantage, and in some cases, may even exclude them from any further academic pursuits. As a result, many researchers are now turning to alternative nonacademic platforms not only to voice their concerns regarding the current uncompromising structure of academia, but also to engage in academic discourses in creative ways that traditional academic jobs do not typically allow.

The social media platform Twitter has become a popular space for academics to keep up to date with research, for public engagement and to build support networks beyond their lab group or department (84). As these topics are still not considered a priority for many institutions or organisations, many critical conversations in academia, and palaeontology specifically, are being carried out on Twitter, for example, those related to mental health (e.g. \#100Voices, @PhD_Balance, \#AcademicMentalHealth), decolonisation and social justice (85-87), and diversity and inclusion, particularly in relation to fieldwork (e.g. @ AbleismAcademia, @ AccessibleGEO, @ aapigeosci, @GeoLatinas, \#BlackInStem, @mothersinsci, @ sacnas). Twitter is now even being used as an alternative to in-person conferences, where "presentations" are in a series of tweets with accompanying graphics and videos and the official conference hashtag (e.g. \#ExOncTC, \#WSTC2, \#PATC1) (88). Such alternative forms of academic discourses prove that scientific communication beyond publications not only appeals to academic audiences, but can also be more effective in terms of public engagement and learning (89). In fact, it is through social media platforms, especially Twitter and Facebook, that many legal issues within palaeontology have come to light. One recent example is that of the illegal status of the "Ubirajara jubatus" specimen through the \#UbirajaraBelongsToBR hashtag on Twitter (30).
A researcher should be appraised on the quality of their work, regardless of where it was published. This is one of the general recommendations of the Declaration on Research Assessment (DORA; https://sfdora.org/), whose aim is to improve the ways in which research and researchers are evaluated. As of 17 May 2021, 19,612 individuals and organisations, including academic publishing groups, are signatories of DORA worldwide. DORA also notes that research output is not only in the form of scholarly articles, but also as dataset production, software development, science communication, and impact on policy, which are all highly relevant to palaeontology. Other factors such as openness and transparency should also play a role in career advancement. This is also imperative for $\mathrm{PhD}$ programs where there is an early emphasis on publication number as a measure of success, which can be detrimental to students' wellbeing and career satisfaction (13). While DORA will not fully solve the overreliance on JIF and other metrics due to the increased labour for those performing the evaluations, the proposed alternatives would place on hiring committees or reviewers (90), it is nonetheless a system that would better serve both science and society.

The increasing visibility of ethical and legal transgressions within our field not only illustrates the fundamental flaws in our academic system, but also how deeply these practices are rooted in colonialism and how they have remained unchanged for centuries (30), which benefits the already powerful and privileged. As we have shown, these transgressions are also inherently encouraged by the current system, which relishes publications over other academic endeavours and where good science is being equated with journal prestige. The ongoing earnest discussions about issues of ethics and legality within palaeontology have only highlighted just how much work we have yet to do; there needs to be a systemic change in the way that palaeontologists operate. Some journals and societies are already ahead of the curve and have been implementing measures to address certain issues. As more and more organisations follow their lead, there will no longer be a tolerance for these illegal and ethical transgressions. In this rapidly evolving climate, transgressors persisting with their unethical and illegal practices will be the first to fall into the "publish and perish" trap.

\section{ACKNOWLEDGEMENTS}

We sincerely thank Jeff Liston for inviting us to contribute to this volume, and Sarah Greene and Rachel Warnock for invaluable discussions and feedback.

\section{DATA AVAILABILITY STATEMENT \\ Data and code for the analyses are available from: https://github.com/paleoscientometrics/paleopubs2021}

\section{References}

1. Seema Rawat and Sanjay Meena. Publish or perish: Where are we heading? Journal of Research in Medical Sciences : The Official Journal of Isfahan University of Medical Sciences, 19(2):87-89, February 2014. ISSN 1735-1995.

2. David Robert Grimes, Chris T. Bauch, and John P. A. loannidis. Modelling science trustworthiness under publish or perish pressure. Royal Society Open Science, 5(1):171511, 2018. doi: 10.1098/rsos.171511. Publisher: Royal Society

3. Gonzalo Génova and José Luis de la Vara. The Problem Is Not Professional Publishing, But 
the Publish-or-Perish Culture. Science and Engineering Ethics, 25(2):617-619, April 2019. ISSN 1471-5546, doi: 10.1007/s11948-017-0015-Z.

4. Meredith T. Niles, Lesley A. Schimanski, Erin C. McKiernan, and Juan Pablo Alperin. Why we publish where we do: Faculty publishing values and their relationship to review, promotion and tenure expectations. PLOS ONE, 15(3):e0228914, March 2020. ISSN 1932-6203. doi: 10.1371/journal.pone.0228914. Publisher: Public Library of Science.

5. Web of Science. The History of ISI, 2021.

6. Wolfgang Glänzel. Seven Myths in Bibliometrics About facts and fiction in quantitative science studies. Collnet Journal of Scientometrics and Information Management, 2(1):9-17, June 2008. ISSN 0973-7766, 2168-930X. doi: 10.1080/09737766.2008.10700836.

7. Björn Brembs, Katherine Button, and Marcus Munafò. Deep impact: unintended consequences of journal rank. Frontiers in Human Neuroscience, 7, 2013. ISSN 1662-5161. doi: 10.3389/fnhum.2013.00291. Publisher: Frontiers.

8. Mark Johnston. We Have Met the Enemy, and It Is Us. Genetics, 194(4):791-792, August 2013. ISSN 0016-6731, 1943-2631. doi: 10.1534/genetics.113.153486. Publisher: Genetics Section: Editorial.

9. John Bohannon. Hate journal impact factors? New study gives you one more reason. Science, July 2016. ISSN 0036-8075, 1095-9203. doi: 10.1126/science.aag0643.

10. David Moher, Florian Naudet, loana A. Cristea, Frank Miedema, John P. A. loannidis, and Steven N. Goodman. Assessing scientists for hiring, promotion, and tenure. PLOS Biology, 16(3):e2004089, March 2018. ISSN 1545-7885. doi: 10.1371/journal.pbio.2004089. Publisher: Public Library of Science.

11. John Tregoning. How will you judge me if not by impact factor? Nature, 558(7710):345-345 June 2018. doi: 10.1038/d41586-018-05467-5. Number: 7710 Publisher: Nature Publishing Group.

12. Paula Stephan, Reinhilde Veugelers, and Jian Wang. Reviewers are blinkered by bibliometrics. Nature News, 544(7651):411, April 2017. doi: 10.1038/544411a. Section: Comment.

13. Anne-Marie Coriat. PhD merit needs to be defined by more than just publications. Nature Human Behaviour, 3(10):1007-1007, October 2019. ISSN 2397-3374. doi: 10.1038/ s41562-019-0727-y. Number: 10 Publisher: Nature Publishing Group.

14. Chiara Franzoni, Giuseppe Scellato, and Paula Stephan. Changing Incentives to Publish Science, 333(6043):702-703, August 2011. ISSN 0036-8075, 1095-9203. doi: 10.1126/ science.1197286. Publisher: American Association for the Advancement of Science Section: Policy Forum.

15. Vincent Larivière, Véronique Kiermer, Catriona J. MacCallum, Marcia McNutt, Mark Patterson, Bernd Pulverer, Sowmya Swaminathan, Stuart Taylor, and Stephen Curry. A simple proposal for the publication of journal citation distributions. preprint, July 2016.

16. Stephen Curry. Let's move beyond the rhetoric: it's time to change how we judge research. Nature, 554(7691):147-147, February 2018. doi: 10.1038/d41586-018-01642-w. Number: 7691 Publisher: Nature Publishing Group.

17. Smriti Mallapaty. China bans cash rewards for publishing papers. Nature, 579(7797):1818, February 2020. doi: 10.1038/d41586-020-00574-8. Number: 7797 Publisher: Nature Publishing Group.

18. Ferric C. Fang and Arturo Casadevall. Retracted Science and the Retraction Index. Infection and Immunity, 79(10):3855-3859, October 2011. ISSN 0019-9567, 1098-5522. doi: 10.1128/IAI.05661-11. Publisher: American Society for Microbiology Journals Section: Editorial.

19. Nature. Why high-profile journals have more retractions. September 2014. ISSN 00280836, 1476-4687.

20. Jeffrey Brainard and Jia You. What a massive database of retracted papers reveals about science publishing's 'death penalty'. Science, October 2018. ISSN 0036-8075, 1095-9203. doi: $10.1126 /$ science aav 8384

21. Melissa S. Anderson, Brian C. Martinson, and Raymond De Vries. Normative Dissonance in Science: Results from a National Survey of U.S. Scientists. Journal of Empirical Research on Human Research Ethics: An International Journal, 2(4):3-14, 2007. ISSN 1556-2646. doi: 10.1525/jer.2007.2.4.3. Publisher: Sage Publications, Inc.

22. Marta Serra-Garcia and Uri Gneezy. Nonreplicable publications are cited more than replicable ones. Science Advances, 7(21):eabd1705, May 2021. ISSN 2375-2548. doi: 10.1126/sciadv.abd1705. Publisher: American Association for the Advancement of Science Section: Research Article.

23. Donna Yates. Dubious dinosaurs, ambiguous amber, and fishy fossils: what creative compliance and neutralization techniques reveal about palaeontological ethics. The Geological Curator.

24. J John Sepkoski, Richard K Bambach, David M Raup, and James W Valentine. Phanerozoic marine diversity and the fossil record. Nature, 293(5832):435-437, 1981. doi: 10.1038/ 293435a0. Publisher: Springer.

25. David M. Raup and J. John Sepkoski. Mass Extinctions in the Marine Fossil Record. Science, 215(4539):1501-1503, March 1982. ISSN 0036-8075, 1095-9203. doi: 10.1126/ science.215.4539.1501. Publisher: American Association for the Advancement of Science Section: Reports.

26. Nature. Editorial criteria and processes | Nature, 2021. ISSN: 1476-4687.

27. Science. Mission and scope, 2021

28. Riley Black. Dinosaur Culture. National Geographic, March 2014. Section: Science.

29. Taiping Gao, Xiangchu Yin, Chungkun Shih, Alexandr P. Rasnitsyn, Xing Xu, Sha Chen, Chen Wang, and Dong Ren. New insects feeding on dinosaur feathers in mid-Cretaceous amber. Nature Communications, 10(1):5424, December 2019. ISSN 2041-1723. doi: 10. 1038/s41467-019-13516-4. Number: 1 Publisher: Nature Publishing Group.

30. Juan Cisnero, Nussaïbah B. Raja, Aline Ghilardi, Emma M. Dunne, Felipe L. Pinheiro, Omar Rafael Regalado Fernández, Marco A. F. Sales, Rubén Rodríguez-de la Rosa, Adriana Y. Miranda-Martínez, Sergio González-Mora, Renan A. M. Bantim, Flavia J. de Lima, and Jason D. Pardo. Digging deeper into colonial paleontological practices in modern day Brazil and Mexico.

31. Kerry Dwan, Douglas G. Altman, Juan A. Arnaiz, Jill Bloom, An-Wen Chan, Eugenia Cronin Evelyne Decullier, Philippa J. Easterbrook, Erik Von Elm, Carrol Gamble, Davina Ghersi, John P. A. Ioannidis, John Simes, and Paula R. Williamson. Systematic review of the empirical evidence of study publication bias and outcome reporting bias. PloS One, 3(8):e3081,
August 2008. ISSN 1932-6203. doi: 10.1371/journal.pone.0003081.

32. Daniele Fanelli. Negative results are disappearing from most disciplines and countries. Scientometrics, 90(3):891-904, March 2012. ISSN 1588-2861. doi: 10.1007/ s11192-011-0494-7.

33. Anzar A. Khuroo, G. H. Dar, Z. S. Khan, and Akhtar H. Malik. Exploring an inherent interface between taxonomy and biodiversity: Current problems and future challenges. Journal for Nature Conservation, 15(4):256-261, December 2007. ISSN 1617-1381. doi: 10.1016/j. jnc.2007.07.003.

34. Lisa W. Drew. Are We Losing the Science of Taxonomy?: As need grows, numbers and training are failing to keep up. BioScience, 61(12):942-946, December 2011. ISSN 00063568. doi: 10.1525/bio.2011.61.12.4.

35. Douglas Zeppelini, Ana Dal Molin, Carlos J. E. Lamas, Carlos Sarmiento, Cristina A Rheims, Daniell R. R. Fernandes, Elison F. B. Lima, Evandro N. Silva, Fernando CarvalhoFilho, L'ubomír Kováč, James Montoya-Lerma, Oana T. Moldovan, Pedro G. B. Souza-Dias, Peterson R. Demite, Rodrigo M. Feitosa, Sarah L. Boyer, Wanda M. Weiner, and William C. Rodrigues. The dilemma of self-citation in taxonomy. Nature Ecology \& Evolution, 5(1):2-2, January 2021. ISSN 2397-334X. doi: 10.1038/s41559-020-01359-y. Number: 1 Publisher: Nature Publishing Group.

36. Ângelo Parise Pinto, Gabriel Mejdalani, Ross Mounce, Luís Fábio Silveira, Luciane Marinoni, and José Albertino Rafael. Are publications on zoological taxonomy under attack? Royal Society Open Science, 8(2):201617, 2021. doi: 10.1098/rsos.201617. Publisher: Royal Society.

37. Lida Xing, Jingmai K. O'Connor, Lars Schmitz, Luis M. Chiappe, Ryan C. McKellar, Qiru Yi, and Gang Li. Hummingbird-sized dinosaur from the Cretaceous period of Myanmar. $\mathrm{Na}$ ture, 579(7798):245-249, March 2020. ISSN 1476-4687. doi: 10.1038/s41586-020-2068-4. Number: 7798 Publisher: Nature Publishing Group.

38. Zhiheng Li, Wei Wang, Han Hu, Min Wang, Hongyu Yi, and Jing Lu. Is Oculudentavis a bird or even archosaur? bioRxiv, page 2020.03.16.993949, March 2020. doi: 10.1101/2020.03. 16.993949. Publisher: Cold Spring Harbor Laboratory Section: Contradictory Results.

39. Lida Xing, Jingmai K. O'Connor, Lars Schmitz, Luis M. Chiappe, Ryan C. McKellar, Qiru Yi, and Gang Li. Retraction Note: Hummingbird-sized dinosaur from the Cretaceous period of Myanmar. Nature, 584(7822):652-652, August 2020. ISSN 1476-4687. doi: 10.1038/ s41586-020-2553-9. Number: 7822 Publisher: Nature Publishing Group.

40. Lucas Joel. Some Paleontologists Seek Halt to Myanmar Amber Fossil Research. The New York Times, March 2020. ISSN 0362-4331.

41. Sam Cooley. Dodging rumour and insurgency: the hunt for Burmese amber goes to the heart of Myanmar's turbulent north, January 2017.

42. Joshua Sokol. Fossils in Burmese amber offer an exquisite view of dinosaur times-and an ethical minefield. Science, May 2019. ISSN 0036-8075, 1095-9203. doi: 10.1126/science. aay1187.

43. Nature. Volume 579 Issue 7798, 12 March 2020, 2020. ISSN: 1476-4687.

44. Emily Rayfield, R., Jessica Theodor, M., and P. David Polly. Society of Vertebrate Paleontology: Fossils from conflict zones and reproducibility of fossil-based scientific data., April 2020.

45. Jacek Szwedo, Bo Wang, Agnieszka Soszyńska-Maj, Dany Azar, and Andrew J. Ross. International Palaeoentomological Society Statement. Palaeoentomology, 3(3):221-222, June 2020. ISSN 2624-2834. doi: 10.11646/palaeoentomology.3.3.1. Number: 3.

46. Carolin Haug, Jelle W. F. Reumer, Joachim T. Haug, Antonio Arillo, Denis Audo, Dany Azar, Viktor Baranov, Rolf Beutel, Sylvain Charbonnier, Rodney Feldmann, Christian Foth, René H. B. Fraaije, Peter Frenzel, Rok Gašparič, Dale E. Greenwalt, Danilo Harms, Matúš Hyžný, John W. M. Jagt, Elena A. Jagt-Yazykova, Ed Jarzembowski, Hans Kerp, Alexander G. Kirejtshuk, Christian Klug, Dmitry S. Kopylov, Ulrich Kotthoff, Jürgen Kriwet, Lutz Kunzmann, Ryan C. McKellar, André Nel, Christian Neumann, Alexander Nützel, Vincent Perrichot, Anna Pint, Oliver Rauhut, Jörg W. Schneider, Frederick R. Schram, Günter Schweigert, Paul Selden, Jacek Szwedo, Barry W. M. van Bakel, Timo van Eldijk, Francisco J. Vega, Bo Wang, Yongdong Wang, Lida Xing, and Mike Reich. Comment on the letter of the Society of Vertebrate Paleontology (SVP) dated April 21, 2020 regarding "Fossils from conflict zones and reproducibility of fossil-based scientific data": the importance of private collections. Paläontologische Zeitschrift, 94(3):413-429, September 2020. ISSN 0031-0220, 1867-6812. doi: 10.1007/s12542-020-00522-x.

47. Joachim T. Haug, Dany Azar, Andrew Ross, Jacek Szwedo, Bo Wang, Antonio Arillo, Viktor Baranov, Julia Bechteler, Rolf Beutel, Vladimir Blagoderov, Xavier Delclòs, Jason Dunlop, Kathrin Feldberg, Rodney Feldmann, Christian Foth, René H. B. Fraaije, Alexander Gehler, Danilo Harms, Lars Hedenäs, Matúš Hyžný, John W. M. Jagt, Elena A. Jagt-Yazykova, Ed Jarzembowski, Hans Kerp, Phyo Kay Khine, Alexander G. Kirejtshuk, Christian Klug, Dmitry S. Kopylov, Ulrich Kotthoff, Jürgen Kriwet, Ryan C. McKellar, André Nel, Christian Neumann, Alexander Nützel, Enrique Peñalver, Vincent Perrichot, Anna Pint, Eugenio Ragazzi, Ledis Regalado, Mike Reich, Jouko Rikkinen, Eva-Maria Sadowski, Alexander R. Schmidt, Harald Schneider, Frederick R. Schram, Günter Schweigert, Paul Selden, Leyla J. Seyfullah, Mónica M. Solórzano-Kraemer, Jeffrey D. Stilwell, Barry W. M. van Bakel, Francisco J. Vega, Yongdong Wang, Lida Xing, and Carolin Haug. Comment on the letter of the Society of Vertebrate Paleontology (SVP) dated April 21, 2020 regarding "Fossils from conflict zones and reproducibility of fossil-based scientific data": Myanmar amber. Paläontologische Zeitschrift, 94(3):431-437, September 2020. ISSN 0031-0220, 1867-6812. doi: 10.1007/s12542-020-00524-9.

48. Paul M. Barrett and Zerina Johanson. Editorial. Journal of Systematic Palaeontology, 18 (13):1059-1059, July 2020. ISSN 1477-2019. doi: 10.1080/14772019.2020.1764313. Publisher: Taylor \& Francis eprint: https://doi.org/10.1080/14772019.2020.1764313.

49. Acta Palaeontologica Polonica. News, 2020.

50. J. J. Liston and Hai-Lu You. Chinese fossil protection law and the illegal export of vertebrate fossils from china. Journal of Vertebrate Paleontology, 35(2):e904791, March 2015. ISSN 0272-4634. doi: 10.1080/02724634.2014.904791. Publisher: Taylor \& Francis eprint: https://doi.org/10.1080/02724634.2014.904791

51. Hanneke Meijer. To collect or not to collect: are fossil-hunting laws hurting science? the Guardian, July 2016. Section: Science.

52. David M. Martill, Helmut Tischlinger, and Nicholas R. Longrich. A Four-Legged Snake from 
the Early Cretaceous of Gondwana. Science, 349(6246):416-419, July 2015. ISSN 00368075, 1095-9203. doi: 10.1126/science.aaa9208. Publisher: American Association for the Advancement of Science Section: Report.

53. Anastasia Christakou. Four-legged snake fossil sparks legal investigation. Nature News, August 2015. doi: 10.1038/nature.2015.18116. Section: News.

54. Robert S. H. Smyth, David M. Martill, Eberhard Frey, Héctor E. Rivera-Sylva, and Norbert Lenz. Temporary Removal: A Maned Theropod Dinosaur from Gondwana with Elaborate Integumentary Structures. Cretaceous Research, page 104686, December 2020. ISSN 0195-6671. doi: 10.1016/j.cretres.2020.104686.

55. Romain Vullo, Eberhard Frey, Christina Ifrim, Margarito A. González González, Eva S. Stinnesbeck, and Wolfgang Stinnesbeck. Manta-like planktivorous sharks in Late Cretaceous oceans. Science, 371(6535):1253-1256, March 2021. ISSN 0036-8075, 1095-9203. doi: 10.1126/science.abc1490. Publisher: American Association for the Advancement of Science Section: Report.

56. Rodrigo Pérez Ortega. Ethical controversy swirls around shark fossil from Mexico. Science, 372(6540):332-333, April 2021. ISSN 0036-8075, 1095-9203. doi: 10.1126/science.372. 6540.332. Publisher: American Association for the Advancement of Science Section: In Depth.

57. Romain Vullo, Eberhard Frey, Christina Ifrim, Margarito A. González González, Eva S. Stinnesbeck, and Wolfgang Stinnesbeck. Erratum for the Report "Manta-like planktivorous sharks in Late Cretaceous oceans" by R. Vullo, E. Frey, C. Ifrim, M. A. González González, E. S. Stinnesbeck, W. Stinnesbeck. Science, 372(6539):eabi9203, April 2021. ISSN 0036 8075, 1095-9203. doi: 10.1126/science.abi9203.

58. Romain Vullo, Eberhard Frey, Christina Ifrim, Margarito A. González González, Eva S. Stinnesbeck, and Wolfgang Stinnesbeck. Supplementary Materials for Manta-like planktivorous sharks in Late Cretaceous oceans (Correction: 8 April 2021), April 2021.

59. Society of Vertebrate Paleontology. Member Bylaw on Ethics Statement, 2015.

60. Paleontological Society. Non-Discrimination and Code of Conduct, 2019.

61. COPE. Committee on Publication Ethics, 2021.

62. Palaeontological Association. Palaeontology: Information for authors, 2021.

63. Cretaceous Research. Author Information, 2021.

64. Tim Hall, Mick Healey, and Margaret Harrison. Fieldwork and disabled students: discourses of exclusion and inclusion. Journal of Geography in Higher Education, 28(2):255-280, July 2004. ISSN 0309-8265. doi: 10.1080/0309826042000242495. Publisher: Routledge_eprint: https://doi.org/10.1080/0309826042000242495.

65. Rachel E. Bernard and Emily H. G. Cooperdock. No progress on diversity in 40 years. Nature Geoscience, 11(5):292-295, May 2018. ISSN 1752-0908. doi: 10.1038/ s41561-018-0116-6. Number: 5 Publisher: Nature Publishing Group.

66. Riley Black. The Many Ways Women Get Left Out of Paleontology. Smithsonian Magazine, June 2018. Section: Articles, Science, Dinosaurs, Women in Science.

67. Riley Black. Queer voices in palaeontology. Nature, July 2019 . doi: 10.1038/ d41586-019-02113-6. Publisher: Nature Publishing Group.

68. Nature. Ban bullying in science, November 2018. Number: 7733 Publisher: Nature Publishing Group.

69. Nussaïbah B. Raja, Emma Dunne, Tasnuva Ming Khan, and Paulina Nätscher. The Overlooked Realities of Sampling Bias in the Fossil Record. page 356351, 2020. doi: 10.1130/abs/2020AM-356351.

70. Natasha Dowey, Jenni Barclay, Ben Fernando, Sam Giles, Jacqueline Houghton, Christopher Jackson, Anjana Khatwa, Anya Lawrence, Keely Mills, Alicia Newton, Steven Rogers, and Rebecca Williams. A UK perspective on tackling the geoscience racial diversity crisis in the Global North. Nature Geoscience, 14(5):256-259, May 2021. ISSN 1752-0908. doi: 10.1038/s41561-021-00737-w. Number: 5 Publisher: Nature Publishing Group.

71. Meredith Wadman. Disturbing allegations of sexual harassment in Antarctica leveled at noted scientist. Science, 2017.

72. Sharon Shattuck, Ian Cheney, and Manette Pottle. Picture a Scientist, 2020.

73. United Nations. Economic interests of the Myanmar military. Technical report, September 2019.

74. Kellia Chiu, Quinn Grundy, and Lisa Bero. 'Spin' in published biomedical literature: A methodological systematic review. PLOS Biology, 15(9):e2002173, September 2017. ISSN 1545-7885. doi: 10.1371/journal.pbio.2002173. Publisher: Public Library of Science.

75. Simon Gandevia. Publication pressure and scientific misconduct: why we need more open governance. Spinal Cord, 56(9):821-822, September 2018. ISSN 1476-5624. doi: 10.1038/ s41393-018-0193-9. Number: 9 Publisher: Nature Publishing Group.

76. J Giles. Breeding cheats. Nature, 445(7125):242-243, January 2007. ISSN 1476-4687. doi: 10.1038/445242a. Number: 7125 Publisher: Nature Publishing Group.

77. Catherine Beaudry and Vincent Larivière. Which gender gap? Factors affecting researchers' scientific impact in science and medicine. Research Policy, 45(9):1790-1817, November 2016. ISSN 0048-7333. doi: 10.1016/j.respol.2016.05.009.

78. Melissa L. Aikens, Melissa M. Robertson, Sona Sadselia, Keiana Watkins, Mara Evans, Christopher R. Runyon, Lillian T. Eby, and Erin L. Dolan. Race and Gender Differences in Undergraduate Research Mentoring Structures and Research Outcomes. CBE-Life Sciences Education, 16(2):ar34, June 2017. doi: 10.1187/cbe.16-07-0211. Publisher: American Society for Cell Biology (Ise).

79. Herman Aguinis, Young Hun Ji, and Harry Joo. Gender productivity gap among star performers in STEM and other scientific fields. Journal of Applied Psychology, 103(12): 1283-1306, 2018. ISSN 1939-1854(Electronic),0021-9010(Print). doi: 10.1037/apl0000331. Place: US Publisher: American Psychological Association.

80. Mike Thelwall and Pardeep Sud. Greater female first author citation advantages do not associate with reduced or reducing gender disparities in academia. Quantitative Science Studies, 1(3):1283-1297, August 2020. ISSN 2641-3337. doi: 10.1162/qss_a_00069.

81. Katherine L. Van Aken. The critical role of creativity in research. MRS Bulletin, 41(12):934938, December 2016. ISSN 0883-7694, 1938-1425. doi: 10.1557/mrs.2016.280. Publisher: Cambridge University Press.

82. Angelika Brechelmacher, Elke Park, Gülay Ates, and David F. J. Campbell. The Rocky Road to Tenure - Career Paths in Academia. In Tatiana Fumasoli, Gaële Goastellec, and Barbara M. Kehm, editors, Academic Work and Careers in Europe: Trends, Challenges, Per- spectives, The Changing Academy - The Changing Academic Profession in International Comparative Perspective, pages 13-40. Springer International Publishing, Cham, 2015. ISBN 978-3-319-10720-2. doi: 10.1007/978-3-319-10720-2_2.

83. European Research Council. Information for Applicants to the Starting and Consolidator Grant 2019 Calls. Technical report, European Commission, October 2018.

84. Esther K. Choo, Megan L. Ranney, Teresa M. Chan, N. Seth Trueger, Amy E. Walsh, Ken Tegtmeyer, Shannon O. McNamara, Ricky Y. Choi, and Christopher L. Carroll. Twitter as a tool for communication and knowledge exchange in academic medicine: A guide for skeptics and novices. Medical Teacher, 37(5):411-416, May 2015. ISSN 0142-159X. doi: 10.3109/0142159X.2014.993371. Publisher: Taylor \& Francis _eprint: https://doi.org/10.3109/0142159X.2014.993371.

85. Aline Ghilardi. Novo dinossauro brasileiro. Fóssil fora do Brasil. Só pesquisador estrangeiro. https://t.co/WFHObE8aYR https://t.co/iiZvGBA3GI, December 2020

86. Aline Ghilardi. "Aline, I'm afraid of being accused of practicing colonialist science without being (or having been) my intention! What should I do?" https://t.co/4GzMxw8ZTU https://t.co/zzreUC9Kzf, April 2021.

87. Yara Haridy. STORY TIME! Many of you may have read the @nytimes article by @asher_elbein: https://t.co/iKppqMHXOD Some of you may want more context as to how "normal" paleo fieldwork became a collapsing museum rescue mission AND case study in how to \#DecolonizePaleontology https://t.co/yYBX07E8os, March 2021.

88. Anthony Caravaggi, Agnes B. Olin, Kirsty A. Franklin, and Steve P. Dudley. Twitter conferences as a low-carbon, far-reaching and inclusive way of communicating research in ornithology and ecology. Ibis, page ibi.12959, May 2021. ISSN 0019-1019, 1474-919X doi: 10.1111/ibi.12959 KerkoCite. ItemAlsoKnownAs: 2664561:AAN6ZH5G 2664561:ZZT8K3WV.

89. Charles G. Knight and Linda K. Kaye. 'To tweet or not to tweet?' A comparison of academics' and students' usage of Twitter in academic contexts. Innovations in Education and Teaching International, 53(2):145-155, March 2016. ISSN 1470-3297. doi: 10.1080/14703297.2014. 928229. Publisher: Routledge.

90. Seppo Ylä-Herttuala. From the Impact Factor to DORA and the Scientific Content of Articles. Molecular Therapy, 23(4):609, April 2015. ISSN 1525-0016. doi: 10.1038/mt.2015.32. 